\title{
Type IIIb Bismuth-Corlette Hilar Cholangiocarcinoma
}

National Cancer Institute

\section{Source}

National Cancer Institute. Type IIIb Bismuth-Corlette Hilar Cholangiocarcinoma. NCI

Thesaurus. Code C134740.

Tumor with type II involvement plus extension to the left 2 nd-order ducts. (AJCC 8th ed.) 